This is an author produced version of a paper published in Environmental Science and Pollution Research.

This paper has been peer-reviewed but may not include the final publisher proof-corrections or pagination.

Citation for the published paper:

Kylin, Henrik, Bouwman, Henk and Evans, Steven W. (2011) Evaluating Threats to an Endangered Species by Proxy: Air Pollution as threat to the Blue Swallow (Hirundo atrocaerulea) in South Africa. Environmental Science and Pollution Research. Volume: 18, pp 282-290.

http://dx.doi.org/10.1007/s11356-010-0369-0.

Access to the published version may require journal subscription.

Published with permission from: Springer Verlag.

Standard set statement from the publisher:

The final publication is available at Springer via http://dx.doi.org/

10.1007/s11356-010-0369-0

Epsilon Open Archive http://epsilon.slu.se 


\title{
Evaluating threats to an endangered species by proxy: Air pollution as threat to the blue swallow (Hirundo atrocaerulea) in South Africa
}

\author{
Henrik Kylin* 1, 2 , Henk Bouwman ${ }^{3}$, Steven W. Evans ${ }^{3}$ \\ ${ }^{1}$ Department of Aquatic Sciences and Assessment, Swedish University of Agricultural \\ Sciences, PO Box 7050, SE-75007 Uppsala, Sweden \\ ${ }^{2}$ Norwegian Institute for Air Research, Polar Environmental Centre, NO-9296 Tromsø, \\ Norway \\ ${ }^{3}$ School of Environmental Sciences and Development (Zoology), North-West University, \\ Private Bag X 6001, Potchefstroom 2520, South Africa
}

*Corresponding author

Phone: +46-70-683 3619

Fax: +46-18-67 3156

henrik.kylin@vatten.slu.se

\begin{abstract}
Background, aim and scope The blue swallow (Hirundo atrocaerulea) is one of the most threatened bird species in southern Africa. Among terrestrial birds, its plumage is known to be the most water repellent, an adaptation to foraging on the wing in dense fog. Despite this unique adaptation, the nesting success of the blue swallow at the Blue Swallow Natural Heritage Site (BSNHS) is lower during years with high incidence of fog. As the phenomenon is not observed at other nesting sites, we hypothesized that this is due to changes in the air chemistry at the BSNHS. In the immediate proximity of the BSNHS plantations of exotic trees (e.g. pines and eucalypts), rich in volatile organic compounds, are a dominant feature. In addition, air pollution from the Johannesburg area is transported with the surface winds and mix with VOCs released from exotic trees. Together with the high humidity and high elevation, these conditions may result in the formation of sulphonates.

Sulphonates are strong detergents and the presence of these in the fog could lead to decreased water repellence of the plumage. This study was performed in order to determine the occurrence and distribution of sulphonates in the BSNHS, and to compare these with sulphonates formed in other locations in South Africa. Because the blue swallow is endangered, pine needles were used as proxy to detect formation of sulphonates.

Methods We sampled pine needles with different exposure to air pollutants, in climates with different humidity, and at different elevation, and analyzed these for sulphonates using mass spectrometry.

Results Pine needles from high elevations and the BSNHS, with high humidity, and exposure to air pollution contained significantly higher concentrations of sulphonates than pine needles from low elevations or from high elevations with a dryer climate or a different combination of air pollutants.

Conclusions These findings lead to two conclusions. Firstly, the occurrence and distribution of sulphonates may be explained by chemical reactions between sulphur dioxide and organic compounds in the humid air induced by ultraviolet radiation. Secondly, elevated concentrations of sulphonates in the fog could affect the water
\end{abstract}


repellence of the blue swallow plumage, possibly decreasing their capacity to forage in the fog. We cannot prove conclusively that this is the reason why the number of blue swallows at the BSNHS has decreased dramatically, but for endangered species we may have to rely on proxies to draw conclusions about outside threats. All such information should be valuable in devising protection plans for species under threat.

Recommendations and perspectives The use of proxies to elucidate threats to endangered species should be evaluated in a broad scale. The mist-belt habitat in general is threatened by many human activities. These findings indicate that air-pollution and the proximity of VOC sources close to mist-belt habitat refuges may be an unrecognised conservation threat to the animals inhabiting them.

Key words Advective fog; Atmospheric chemistry; Forest plantation; Mist-belt habitat encroachment; Sulphonate formation; Sulphur dioxide

\section{Background, aim and scope}

The blue swallow (Hirundo atrocaerulea) is one of the most threatened bird species in southern Africa. It is globally vulnerable (BirdLife International 2008) and one of five critically endangered bird species in South Africa (Evans and Barnes 2000). Nests are built in existing holes such as sinkholes or aardvark burrows in mist-belt grasslands such as highelevation (highveld) grasslands of the eastern escarpment of the Southern African Plateau (Driver et al. 2004; Evans and Bouwman in press a), with high rainfall ( $>1000 \mathrm{~mm}$ per annuum) and high incidence of advective fog. Suitable nesting habitats are thinly dispersed from South Africa north to south-eastern Democratic Republic of the Congo (Turner and Rose 1989; Keith et al. 1992; BirdLife International 2008). The blue swallow is an intra-African migrant. When not nesting, between April-September for South African birds, the birds migrate north to the Lake Victoria Basin, and the north-eastern Democratic Republic of the Congo (Spottiswoode 2005; Evans and Bouwman in press b). Throughout their range, the habitat of the blue swallow is threatened by infringing agriculture, wetland reclamation, overgrazing, and urbanisation. Additionally in South Africa, blue swallow habitat is threatened by mining and planting of exotic tree species (Evans and Barnes 2000; Spottiswoode 2005; Wakelin and Hill 2007).Due to the scarcity of suitable habitats, the species has probably never been numerous. Today, the world population is 'optimistically' estimated at 1000 pairs (Evans and Barnes 2000).

The blue swallow forages on the wing, flying slowly and close to the ground, often in dense fog. Foraging is limited to an area not further than $1.5 \mathrm{~km}$ away from the nest even during fog periods (SW Evans, unpublished data). Water repellent plumage is a key adaptation that enables the blue swallow to fly in dense fog. The plumage is nearly as water repellent as that of waterfowl (Rijke et al. 2000), which is unique among terrestrial birds.

At the time of European settlement, only $0.1 \%$ of South Africa was covered with natural closed-canopy forests, but since the First World War, much of the original grasslands have been planted with exotic trees for timber and timber products, to such an extent that $1.25 \%$ (1.5 million ha) is now under exotic plantation (Tewari 2001). The prime forestry intrudes into biodiversity-rich high-lying grasslands, including the Drakensberg Escarpment of Mpumalanga (Tewari 2001; Driver et al. 2004). Only 2\% of South Africa's grassland biome is formally protected, but half of South Africa's endemic mammals, a third of its butterflies, and 10 of its 14 globally threatened bird species occur there (O’Connor and Kuyler 2009). Forestry in Mpumalanga has had significant impact on bird biodiversity mainly due to plantations taking over natural climax grasslands (Allan et al. 1997).

The Blue Swallow Natural Heritage Site (BSNHS, Fig. 1) was established in 1986 and is located on the edge of the Drakensberg Escarpment in Mpumalanga province, South Africa. 
At the time, this was one of the most important strongholds of the blue swallow in South Africa, many nesting in abandoned artisan mine shafts.

The mist-belt grasslands at the BSNHS are the remains of what used to be more extensive grasslands along the escarpment, but parts have been planted with exotic trees, mostly pines, acacias, and eucalypts to supply industry. To the west of the escarpment is the South African Plateau with a mean elevation of about $1200 \mathrm{~m}$; to the east are the coastal plains of Mozambique that rise slowly from the sea level to the escarpment (Tyson et al. 1988). Warm, humid trade winds from the Indian Ocean blow across the coastal plains and are forced upwards at the escarpment forming dense advective fog, a prerequisite for the mist-belt habitats. As the trade winds are forced upwards, a back draft is created so that the predominant near ground winds over the plateau are from the west (Fig. 2). These westerly winds carry pollutants from the industrial areas around Johannesburg and the Highveld areas of Mpumalanga, including sulphur dioxide $\left(\mathrm{SO}_{2}\right)$ from smelters, petrochemical industries, mining and power plants burning coal (Freiman and Piketh 2002; Rorich and Galpin 1998; Tyson et al. 1988; Zunkel et al. 2000). In addition, although site-specific data are lacking, it is highly likely that the introduction of exotic trees rich in volatile terpenoids into areas naturally dominated by grasses have increased the amount of volatile organic compounds (VOCs) in the air (Guenther et al. 1999, Lelieveld et al. 2008, Zunkel et al. 2007).

In the1990s, the nesting success of the blue swallow decreased during years with much fog (Evans and Bouwman 2000). Evans and Bouwman (2000) speculated that the presence of anthropogenic pollutants and a recent increase of VOCs in the air at BSNHS altered the chemistry of the fog so that the capacity of the swallow's plumage to resist wetting was decreased.

A compound class that could increase the wettability of the blue swallow plumage is sulphonic acids, mainly present in the sulphonate form at environmental $\mathrm{pH}$. Sulphonates are surface active and important as active components in many detergents (Gilbert 1965, Patai and Rappoport 1991). There are several reactions by which sulphonates may be formed in situ at the BSNHS. For example, secondary alkane sulphonates can be formed by a reaction initiated by ultraviolet (UV) radiation $(366 \mathrm{~nm})$ that will give secondary alkane sulphonates using alkanes, sulphur dioxide ( $\left.\mathrm{SO}_{2}\right)$, water, and oxygen as raw materials (Orthner 1950), according to the overall scheme in Figure 3. By planting exotic trees emitting VOCs and the transport of $\mathrm{SO}_{2}$ from the Johannesburg area (see above) we hypothesized that a situation is created at the BSNHS, which, because of its high elevation and location already had high humidity and UV radiation, promotes the formation of sulphonates.

Sulphonates and other compounds with detergent properties accumulate in the surface film of the fog droplets (Latif and Brimblecombe 2004, Lo and Lee 1996), thereby reducing the surface tension of the droplets, allowing water to penetrate into the plumage. Thus, they are present precisely where they would do most harm to foraging blue swallows, and even a small increase in the sulphonate levels could compromise water repellency and make foraging in dense fog more energy consuming.

This study was undertaken to determine if sulphonic acids are formed by abiotic chemical processes in the air at the BSNHS, and whether this process may negatively affect the blue swallow. However, as the number of swallows is low and dwindling, it is neither advisable nor ethical to perform studies on the swallows themselves. In the absence of any environmental monitoring programme that could measure the presence of sulphonates in the fog we searched for a proxy that would allow us to investigate the differences between the blue swallow habitat and other areas of South Africa. Previous experience (Kylin 1994) had shown that the occurrence of sulphonates in the air may be traced by the analysis of pine needles. We, therefore, chose pine needles exposed to the same fog regime as the blue 
swallows at the BHNHS as proxy for the blue swallow and compared with needles from other parts of South Africa to evaluate the situation at the BSNHS.

\section{Materials and methods}

\subsection{Sample collection}

Pine needles (Pinus sp., see further section 3.2) were collected from 1.5-2 m height in trees located at the edge of plantation stands in November 1997. Samples were collected at different elevations from about $1700 \mathrm{~m}$ to $1000 \mathrm{~m}$ above sea level along a back road through a sheltered valley westward from the BSNHS mist-belt to Ngodwana (Fig. 1). Samples were also collected down to an elevation of 1500 m east of the BSNHS on the humid escarpment slope facing the Indian Ocean. On the eastward face of the escarpment, the winds are mainly regional carrying humid air from the coastal plain, while the winds in the valley are predominantly local with little humidity (Tyson et al. 1988). At each site, samples were taken from one to three individual trees. The plantations were of fairly uniform age, and no age distinction was made in the sampling.

Additional samples were collected from other parts of South Africa, at lower elevations, near pollution sources, and in humid and dry climates, to verify elevation and microclimate effects on sulphonate formation (see Table 1 for additional information on locations).

Whole twigs with needles were collected and transported to the lab where the needles were removed, separated into year-classes, and air-dried at room temperature until constant mass was obtained. To standardise the length of exposure to air pollutants only one-year old (after emergence) needles were used for this study. Subsamples (5 $\mathrm{g} \mathrm{dr}$. w.) of needles were packed in envelopes of aluminium foil. The envelopes were stored in polyethylene bags in a freezer until further processing could take place.

\subsection{Sample work-up}

The epicuticular wax was washed off the needles with dichloromethane (DCM). The amount of needles extracted of each sample group was adjusted $(5-25 \mathrm{~g})$ to give a good signal to noise ratio within the linear range of the method. The volume of DCM was reduced to $3 \mathrm{ml}$ under a slow stream of nitrogen, and the acidic compounds extracted out of the DCM with sodium hydroxide $(0.01 \mathrm{~mol} / \mathrm{l})$ in water $(4 \mathrm{ml})$ in a $12-\mathrm{ml}$ test tube with a Teflon-lined screw cap. The long-chain acids in the wax will dissolve neither in the water phase nor in the organic phase, but it is possible to separate the phases by centrifugation. After centrifugation (800 rpm for $2 \mathrm{~min}$ ) the organic phase was removed, the water phase washed with additional DCM (5 ml), which was also removed after centrifugation. The water phase was acidified by drop-wise addition of hydrochloric acid (6 mol/l), the acidic wax components re-extracted into DCM (2 x $5 \mathrm{ml})$, and the DCM volume reduced to approximately $2 \mathrm{ml}$ under a slow stream of nitrogen.

Trifluorodiazoethane (TFDE), was synthesised from 2,2,2-trifluoroethylamine hydrochloride and sodium nitrite (Gilman and Jones 1943, Meese 1984). This reagent will react with sulphonic acids, but not with other acidic functional groups such as carboxylic acids that are the dominant acidic functionality in epicuticular wax (Meese 1984). The TFDE in diethyl ether was added drop-wise to the DCM solution of acidic wax components until a yellow colour persisted for more than $90 \mathrm{~min}$. Heptafluorobutyl-p-toluenesulphonate (HFBTS), was synthesised from p-toluenesulphonylchloride and 2,2,3,3,4,4,4heptafluorobutanol (Tiers et al. 1953), and a known amount was added to each sample as internal standard. All solvents and reagents were from Kebo, Spånga, Sweden. 


\subsection{Quantification}

Quantification of the sulphonate groups in the wax was on a TSQ700 triple quadropole mass spectrometer (Finnigan, San Jose, CA, USA) operated in the single quadrupole mode using a direct inlet probe with ballistic heating to $300{ }^{\circ} \mathrm{C}$ and negative ion chemical ionization (NCI) using methane as reactant gas. Negative ion chemical ionization of trifluoroethyl sulphonates gives a characteristic fragment at $\mathrm{m} / \mathrm{z} 163\left(\left[\mathrm{C}_{2} \mathrm{H}_{2} \mathrm{~F}_{3} \mathrm{SO}_{3}\right]^{-}\right)$, while HFBTS gives a fragment at $\mathrm{m} / \mathrm{z} 263\left(\left[\mathrm{C}_{4} \mathrm{H}_{2} \mathrm{~F}_{7} \mathrm{SO}_{3}\right]^{-}\right)$. There are very few other fragments in the respective negative ion mass spectra. The area under the selected ion traces for $\mathrm{m} / \mathrm{z} 163$ and 263 were determined manually. Quantification was done with a five point calibration curve constructed using a known amount of secondary alkyl sulphonate (SAS, chain length $\mathrm{C}_{11}-\mathrm{C}_{15}$, Nordtend AB, Stockholm, Sweden) treated as a wax sample to which a known amount of HFBTS was added as internal standard.

\subsection{Statistical analysis}

Statistical analysis of the data from the elevation transect was done with Prism 4 (GraphPad Software). A linear regression of the sulphonate concentrations in wax from the western part of the BSNHS was performed against elevation (32 values). Data per elevation interval was normally distributed and therefore not transformed.

\subsection{Quality assurance and control}

Sample surrogates were prepared by an independent person. These consisted of two known concentrations of SAS added to a wax sample that previously had been shown to be free from sulphonates. The samples were run several times and the concentrations were not revealed to the analyst until the samples had been run (Table 2).

For each group of samples (i.e., samples from the same elevation or sampling location) a test series was first run to ensure that the quantification (the addition of HFBTS) would be within the linear range (more than two orders of magnitude) of the method. After this precalibration, the order in which samples from different elevations and sampling areas were run was random.

\section{Results and discussion}

\subsection{Analytical methodology}

The analytical method cannot discriminate between different types of sulphonates. The reason for choosing such a method is that the reactions that would form sulphonates from the reactants present in the air at the BSNHS will not form any specific compound. A sulphonate group can be formed at any secondary carbon (i.e., a carbon atom that binds to two other carbon atoms with single bonds) available (Orthner 1950), and the number of different types of secondary carbons, both in the epicuticular wax and in the VOCs emitted from the trees, is very high. Therefore, a method that can quantify the total number of sulphonate groups, irrespective of which hydrocarbon moiety the sulphonate is bound to is necessary.

\subsection{Sulphonate distribution}

The results (Table 1, Fig. 4) indicate that sulphonates are formed in situ at the BSNHS. The sulphonate concentrations (measured as nmol/g wax) were an order of magnitude higher in the mist-belt at $1600-1700 \mathrm{~m}$ than at elevations below $1200 \mathrm{~m}$ from the same locality. The slope of the linear regression (Fig. 4) was positive and significantly different from zero $(\mathrm{P}<0.0001)$ and the $\mathrm{r}^{2}$ was 0.876 (Fig. 4). A runs test showed that the regression was not significantly non-linear ( $\mathrm{p}=0.5074)$, showing that a linear model was the best fit. To test whether error in $\mathrm{x}$ would have any significant effect, a Deming regression was also 
performed, using $100 \mathrm{~m}$ as the standard deviation for $\mathrm{X}$ (elevation), and 0.13 as standard deviation for Y (Table 1; the largest standard deviation of any of the three mean elevation concentrations). Slope was again significant ( $<<0.0001 ; \mathrm{r}^{2}$ cannot be calculated), and again, a linear model showed the best fit $(\mathrm{p}=0.5781)$. This regression shows a significant increase in sulphonate concentrations in wax with an increase in elevation.

The concentrations of sulphonates in pine needles from other parts of South Africa were also lower than those from the BSNHS mist-belt. The concentrations of sulphonates at 1500 m elevation on the eastern, humid side of the escarpment were similar to those in the mistbelt, while they were somewhat lower at the same elevation in the valley where there is lest fog. This indicates that the air humidity is a key factor for the formation of sulphonates. However, humidity itself is not sufficient as shown by the low levels of sulphonates in the samples collected at Jozini that has a humid climate, but with lower UV-radiation and concentrations of VOCs from exotic trees, and much further located from any large anthropogenic $\mathrm{SO}_{2}$ sources. Further, the absence of sulphonates at Pilanesberg (in the much drier north-west) shows that UV-radiation alone is not sufficient, and the results from Ulundi show that UV-radiation in combination with humidity is not sufficient. All samples were collected from rural areas. The exception was, perhaps, the sample collected northeast of Pretoria. Although outside the metropolitan area itself, the influence of the highly populated and industrialised Johannesburg/Pretoria area may be such that direct release of sulphonates from industries and households gives this sample location a slightly higher sulphonate concentration than the other samples outside of the BSNHS transect.

A reasonable explanation for the sulphonate distribution found in this study is that they are formed under the specific combination of conditions that are present at the BSNHS. Key elements are high humidity and UV-radiation (advective fog associated with high elevation) in combination with the presence of $\mathrm{SO}_{2}$ and hydrocarbons. The specific combination of conditions present in the mist-belt at the BSNHS exists neither at the lower elevations along the elevation gradient, nor at any of the other locations in South Africa. Previous experience from Europe also showed that the highest concentrations of sulphonates were found at high elevation sites with advective fog formation (Kylin 1994).

A confounding factor could be that different species of pines are planted at the different elevations of the transect and in other areas of the country as they are adapted to different local climates. But tests of the concentration of sulphonates in needles from different pine species grown in three botanical gardens from different parts of Europe showed no difference between different pine species or trees of different age grown at the same locality (Kylin unpublished data). It is, therefore, reasonable to assume that the species would be comparable in this study too. Further, there was a considerable overlap of species and more than one species was sampled in all of the divisions of the elevation transect, but no differences could be seen between the different species at each elevation.

\subsection{Consequences for species preservation}

At other sites in South Africa, the few remaining populations of blue swallow are maintaining themselves, but the population at the BSNHS has taken a dramatic plunge during recent years. In the austral summer of 2008-2009, only one pair was nesting at the site. The presence of sulphonates in pine needles is, however, not unequivocal evidence that the wettability of the plumage of the blue swallow is compromised. Neither do we have any direct evidence that increased plumage wettability would affect the swallows foraging capacity. However, this study indicates that sulphonates are formed in situ under the conditions found at the BSNHS.

The ideal investigation would include measurements of the wettability of the plumage of live swallows and continuous monitoring of the air pollution situation, including the fog water chemistry, at the BSNHS. However, establishing an environmental monitoring programme 
that could answer the relevant questions would be very costly and it would take several years before sufficient data have been collected for a meaningful evaluation. Also, because of the low number of birds and few individuals at each location, catching individual swallows to measure the wettability of their plumage would risk influencing the population even more negatively than the air pollutants. Because of the challenges faced when measuring the effects of air pollution directly on endangered blue swallows, proxies such as pine needles or alternative avian species may provide useful information on this and other factors that may be affecting the blue swallow population in the BSNHS.

At present, this type of study, using pine needles as proxy for blue swallow plumage, can at least serve to strengthen the previous proposition (Evans and Bouwman 2000) that the nesting success of the blue swallow may be influenced by air pollutants. Discussions on habitat preservation should take this into account.

The proximity of air-pollution and VOC sources close to mist-belt regions may be an unrecognised conservation threat to the birds inhabiting them. Habitat change from primarily grasslands to plantations would also probably increase the VOC releases per surface area (Guenther et al. 1999, Lelieveld et al. 2008). An increase in industrial and transportation SO2 release sources surrounding the BSNHS, in combination with sources of VOCs are likely to increase the rate of sulphonate formation, and augment the threat it may pose to mist-belt birds. Higher global temperatures could also increase VOC production (Guenther et al. 1999), increasing the amount of hydrocarbons available in the air. The same conditions may also be present in other regions of the globe where fog or clouds interact with birds, such as in Indonesia (Paulsen and Lambert 2000), Guatemala (Eisermann and Schulz 2005, Renner et al. 2006) and Mexico (Martinez-Morales 2005). Ingestion of mist-carried pollutants indirectly from contaminated food (Llacuna et al. 1995) or from preening feathers wetted by fog droplets may pose additional risks to birds in the BSNHS and similar habitats.

\section{Conclusions}

The presence of significantly higher concentrations of strong detergents in the vegetation at the BHNHS than at the other sampling sites, both in the elevation transect and in other parts of South Africa, indicate that these compounds have been formed in situ in this important blue swallow habitat. This strengthens the suggestion that changes in air chemistry at the BSNHS decreases the nesting success of the blue swallow. Although the evidence presented here cannot be viewed as conclusive, difficulties to obtain unequivocal evidence about environmental problems are common. Dealing with an endangered species, even evidence that is not conclusive, perhaps based on proxy, may be valuable to develop precautionary protection schemes.

\section{Recommendations and perspectives}

The emissions of sulfur dioxide from the industries around Johannesburg are a consequence of activities that are imperative to the country's economy. These industrial activities will most certainly continue, but the threat to the blue swallow could be an additional argument to reduce the emissions when new investments are to be made. Large opencast coal mining close to escarpment and in the grassland biome is planned, although heavily opposed by conservationists and locals. Wakkerstroom and Chrissiesmeer, both Important Bird Areas and potential Ramsar sites, are likely to suffer from additional disturbance and $\mathrm{SO}_{2}$ releases.

The planting of exotic trees is also of great economic value to South Africa. These plantations constitute a problem to the blue swallow already as an infringement on its habitat, but planting species that emit large quantities of VOCs close to nesting sites may aggravate 
the problem. Development or rehabilitation of plantations will probably not stop, but discussions could be taken up with the plantation operators to find other tree species with lower VOC emissions to be planted around known or potential nesting areas to as far as possible reduce problems for the birds.

Since South Africa hosts most of the few conserved blue swallow breeding sites, any air pollution impact here could affect the global population. Using pine needles as a proxy at BSNHS and at other potentially impacted sites would advance the knowledge of a physical impact of chemicals on the flight parameters of the endangered blue swallow and similar birds.

Acknowledgements Parts of this study were funded by grants from the South African National Research Foundation, the North-West University, and the Swedish Royal Academy of Sciences. Hannetjie Botha helped find funding, while Lars Sonesten and an unknown reviewer gave valuable comments on the manuscript.

\section{References}

Allan DG, Harrison JA, Navarro RA, van Wilgen BW, Thompson MW (1997) The impact of commercial afforestation on bird populations in Mpumalanga province, South Africa - insights from bird atlas data. Biol Conser 79:173-185

BirdLife International (2008) Hirundo atrocaerulea. IUCN Red List of Threatened Species, www.iucnredlist.org

Eisermann K, Schulz U (2005) Birds of a high-altitude forest in Alta Verapaz, Guatamala. Rev Biol Trop 53:577-594

Evans SW, Barnes KN (2000) Blue swallow. In: Barnes KN (ed) The Eskom Red Data Book of birds of South Africa, Lesotho and Swaziland. Birdlife South Africa, Johannesburg

Evans SW, Bouwman H (2000) The influence of mist and rain on the reproductive success of the blue swallow Hirundo atrocaerulea. Ostrich 71:83-86.

Evans SW, Bouwman H (in press a) Habitat selection by blue swallows Hirundo atrocaerulea Sundevall 1850, breeding in South Africa and its implications for conservation. Afr J Ecol doi: 10.1111/j.13652028.2009.01183.x

Evans SW, Bouwman, H (in press b) Historical and current distribution, population size, and possible migration routes of the Blue Swallow Hirundo atrocaerulea in Africa. Bird Conserv Int doi:10.1017/S0959270910000158

Freiman MT, Piketh SJ (2003) Air transport into and out of the industrial Highveld region of South Africa. J Appl Meteorol 42:994-1002.

Gilbert EE (1943) Sulfonation and related reactions. Wiley Interscience, New York; 1965. p. 125-199

Gilman H, Jones RG (1943) 2,2,2-Trifluoroethylamine and 2,2,2-Trifluorodiazoethane. J Am Chem Soc 65:1458-1460.

Guenther A, Archer S, Greenberg J, Harley P, Helmig D, Klinger L, Vierling L, Wildermuth M, Zimmerman P, Zitzer S (1999) Biogenic hydrocarbon emissions and landcover/climate change in a subtropical savanna. Phys Chem Earth (B) 24:659-667

Keith S, Urban EK, Fry CH (1992) The birds of Africa. Vol IV. Academic Press, London

Kylin H (1994) Lipophilic air pollutants in pine needles. Thesis, Stockholm University, Sweden

Llacuna S, Gorriz A, Sanpera C, Nadal J (1995) Metal accumulation in three species of passerine birds (Emberiza cia, Parus major, and Turdus merula) subjected to air-pollution from a coal-fired power station. Arch Environ Contam Toxocol 28:298-303

Latif MT, Brimblecomb P 2004 Surfactants in atmospheric aerosols. Environ Sci Technol 38:6501-6506

Lelieveld J, Butler TM, Crowley JN, Dillon TJ, Fisher H, Ganzeveld L, Harder H, Lawrence MG, Martinez M, Taraborreli D, Williams J (2008) Atmospheric oxidation capacity sustained by a tropical forest. Nature 452:737-740

Lo J-HA, Lee W-MG (1996) Effect of surfactant film solubility of hydrophobic organic compounds in fog droplets. Chemosphere 33:1391-1408

Martinez-Morales MA (2005) Landscape patterns influencing bird assemblages in a fragmented neotropical cloud forest. Biol Conserv 121:117-126

Meese CO (1984) 2,2,2-Trifluorodiazoethane: a highly selective reagent for the protection of sulfonic acids. Synthesis 12:1041-1042 
O’Connor TG, Kuyler P (2009) Impact of land use on the biodiversity of integrity of the moist sub-biome of the grassland biome, South Africa. J Environ Manage 90:384-395

Orthner L (1950) Die Einführung von Sulfo-Gruppen in Alkane mittels Schwefeldioxyd und Sauerstoff (Sulfoxydation). Angew Chem 62:302-305

Patai S, Rappoport Z (eds) (1991) The Chemistry of Sulphonic Acids, Esters and Their Derivatives. Wiley, New York

Paulsen MK, Lambert FR (2000) Altitudinal distribution and habitat preferences of forest birds on Hlamahera and Buru, Indonesia: implications for conservation of Moluccan avifaunas. Ibis 142:566-586

Preston-Whyte RA, Tyson PD (1988) The atmosphere and weather of southern Africa. Oxford University Press, Cape Town, South Africa

Renner SC, Waltert M, Muhlenburg M (2006) Comparison of bird communities in primary vs. young secondary tropical montane cloud forest in Guatemala. Biodiv Conserv 15:1545-1575

Rijke AM, Jesser WA, Evans SW, Bouwman H (2000) Water repellency and feather structure of the blue swallow Hirundo atrocaerulea. Ostrich 71:143-145

Rorich RP, Galpin JS (1998) Air Quality in the Mpumalanga Highveld region, South Africa. S Afr J Sci 94:109114

Spottiswoode CN (2005) Blue swallow Hirundo atrocaerulea. In: Hockey PAR, Dean WRJ, Ryan PG. (eds) Roberts - birds of southern Africa, VII. The trustees of the John Voelcker Bird Book Fund, Cape Town, South Africa

Tewari DD (2001) Is commercial forestry sustainable in South Africa? The changing institutional and policy needs. Forest Policy Econ 2:333-353

Tiers GVD, Brown HA, Reid TS (1953) 1,1-di-H-perfluoroalkyl halides. J Am Chem Soc75:5978-5979

Turner A, Rose C. (1989) A handbook to the swallows and martins of the world. Christopher Helm, London

Tyson PD, Kruger FJ, Louw CW (1988) Atmospheric pollution and its implications in the Eastern Transvaal Highveld. South African National Scientific Programmes Report. No. 150. Foundation for Research Development, Pretoria, South Africa

Wakelin J, Hill TR (2007) The impact of land transformation on breeding blue swallows Hirundo atrocaerulea Sundevall, in KwaZulu-Natal, South Africa. J Nat Conserv 15:245-255

Zunkel M, Robertson L, Tyson PD, Rodhe H (2000) Modelled transport and deposition of sulphur over Southern Africa. Atmos Environ 34:2797-2808

Zunckel M, Chiloane K, Sowden M, Otter L (2007) Biogenic volatile organic compounds: The state of knowledge in southern Africa and the challenges for air quality management. S Afr J Sci 103:107-112 
Table 1 Mean concentrations of sulphonate groups in pine needle epicuticular wax at the Blue Swallow National Historic Site (BSNHS) and other locations in South Africa.

\begin{tabular}{|c|c|c|c|c|c|c|}
\hline \multirow[t]{2}{*}{ Location } & \multicolumn{2}{|c|}{ Coordinates $^{\mathrm{a}}$} & \multirow{2}{*}{$\begin{array}{c}\text { Elevation } \\
\text { (m asl) }\end{array}$} & \multirow[t]{2}{*}{ Site characteristics } & \multirow[t]{2}{*}{$\mathrm{n}$} & \multirow{2}{*}{$\begin{array}{c}\text { Mean concentration } \pm 95 \% \\
\text { confidence interval } \\
\text { (nmol/g wax) }\end{array}$} \\
\hline & S & $\mathrm{E}$ & & & & \\
\hline \multirow[t]{4}{*}{ BSNHS } & $25^{\circ} 37^{\prime} 35^{\prime \prime}$ & $30^{\circ} 45^{\prime} 17^{\prime \prime}$ & 1500 & Eastern humid slope & 3 & $0.88 \pm 0.28$ \\
\hline & & & $1600-1700$ & Mist-belt & 14 & $0.87 \pm 0.12$ \\
\hline & & & $1300-1500$ & Valley west of mist-belt, dry climate & 8 & $0.45 \pm 0.13$ \\
\hline & & & $1000-1200$ & Valley bottom, dry climate & 10 & $0.08 \pm 0.02$ \\
\hline Jozini & $27^{\circ} 26^{\prime} 52^{\prime \prime}$ & $32^{\circ} 08^{\prime} 40^{\prime \prime}$ & 80 & High humidity lowland area & 2 & n.d. ${ }^{b}$ \\
\hline Ulundi & $28^{\circ} 18^{\prime} 09^{\prime}$, & $31^{\circ} 28^{\prime} 46^{\prime \prime}$ & 500 & Medium elevation, fairly dry climate & 2 & trace $^{\mathrm{c}}$ \\
\hline Pretoria & $25^{\circ} 36^{\prime} 55^{\prime \prime}$ & $28^{\circ} 22^{\prime} 16^{\prime \prime}$ & 1200 & High elevation, dry climate & 3 & $0.15 \pm 0.07^{d}$ \\
\hline Pilanesberg & $25^{\circ} 14^{\prime} 18^{\prime \prime}$ & $27^{\circ} 16^{\prime} 05^{\prime \prime}$ & 1100 & High elevation, dry climate & 2 & n.d. \\
\hline
\end{tabular}

${ }^{a}$ As several samples were collected from each elevation, coordinates given for the sampling around the BSNHS refers to the centre of the BSNHS proper.

b Not detected $(<0.003 \mathrm{nmol} / \mathrm{g})$

c $0.003 \mathrm{nmol} / \mathrm{g}<$ trace $<0.015 \mathrm{nmol} / \mathrm{g}$

${ }^{\mathrm{d}}$ Possible local pollution sources

Table 2 Quality assurance tests with surrogate samples of wax with added secondary alkyl sulphonate.

\begin{tabular}{cccc}
\hline $\begin{array}{c}\text { Target conc. } \\
\text { nmol/g }\end{array}$ & $\begin{array}{c}\text { Found conc. (mean) } \\
\text { nmol/g }\end{array}$ & n & $\begin{array}{c}\text { Relative standard deviation } \\
(\%)\end{array}$ \\
\hline 0.22 & 0.18 & 5 & 25 \\
0.63 & 0.65 & 8 & 13 \\
\hline
\end{tabular}




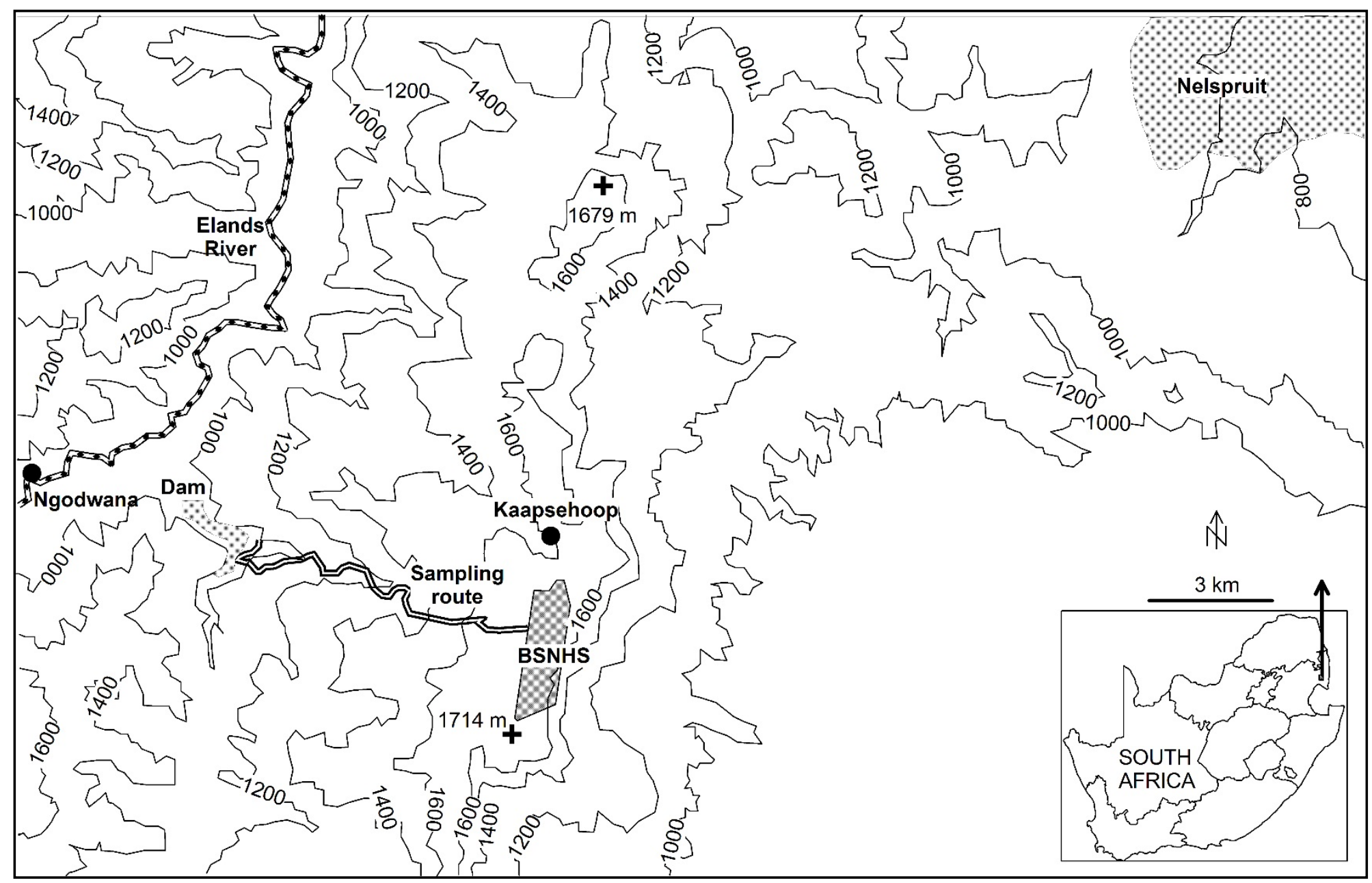

Fig. 1 Location of the Blue Swallow Natural Historic Site (BSNHS). Samples in the elevation gradient were taken along the road shown on the map. 

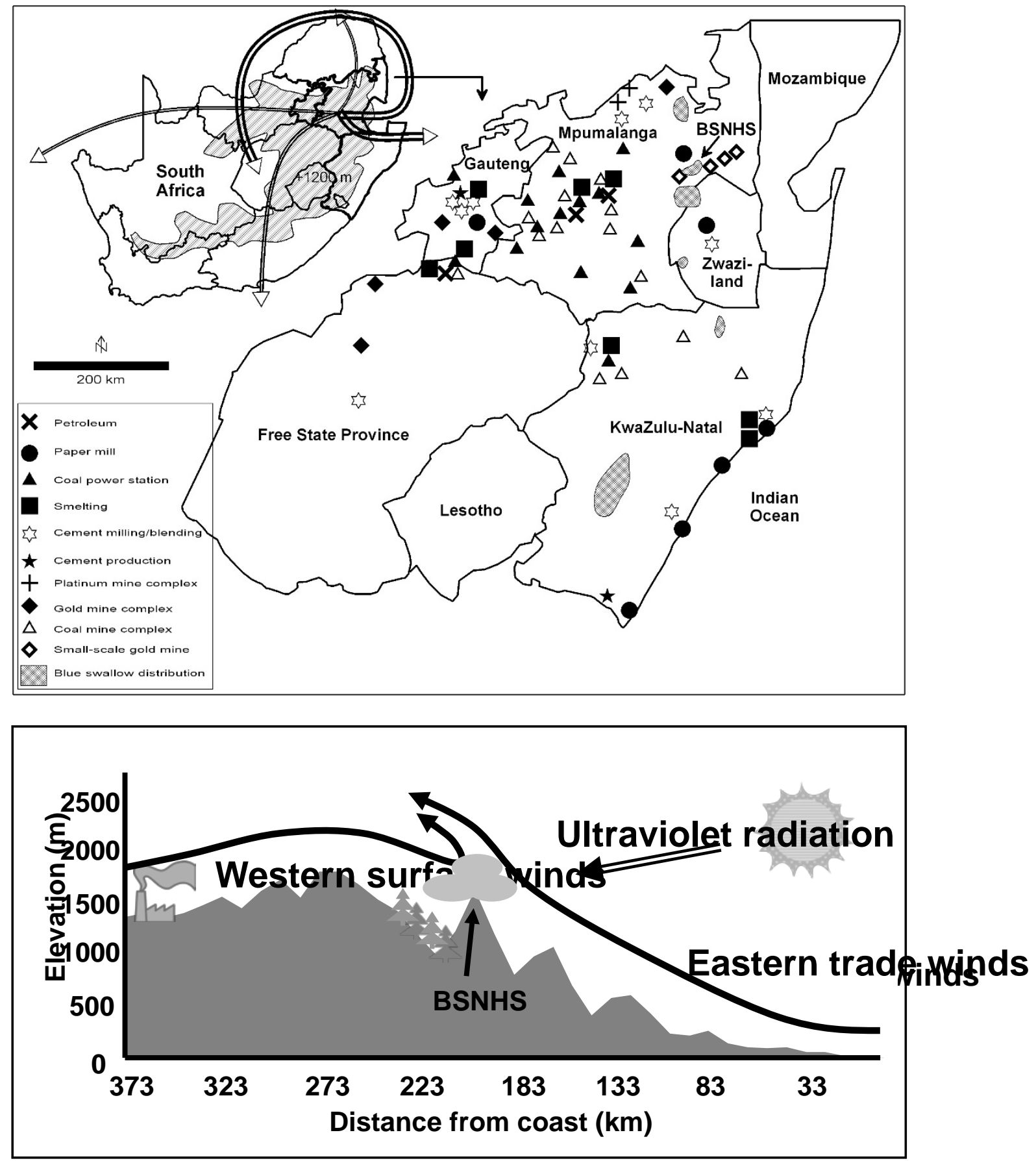

Fig. 2 The circulation pattern over South Africa. Upper panel: Sources of pollution in eastern South Africa. Arrows indicate volume and direction of air transported out of the heavily industrialised Highveld area. The South African Plateau with an elevation higher than $1200 \mathrm{~m}$ is indicated in the upper left hand corner. Lower panel: Schematic of wind patterns and formation of advective fog at the Blue Swallow National Historic Site. 


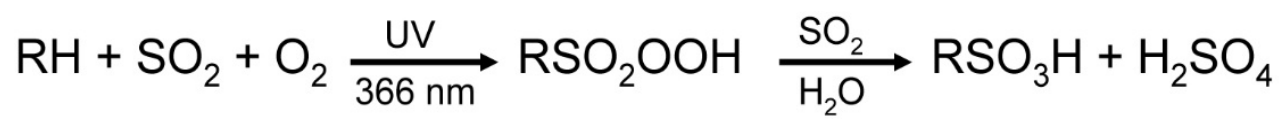

Fig. 3 Overall reaction scheme of sulphoxidation, a reaction by which alkyl sulphonates are formed from a alkane (RH) sulphur dioxide, water, and oxygen under the influence of ultraviolet radiation (366 nm).

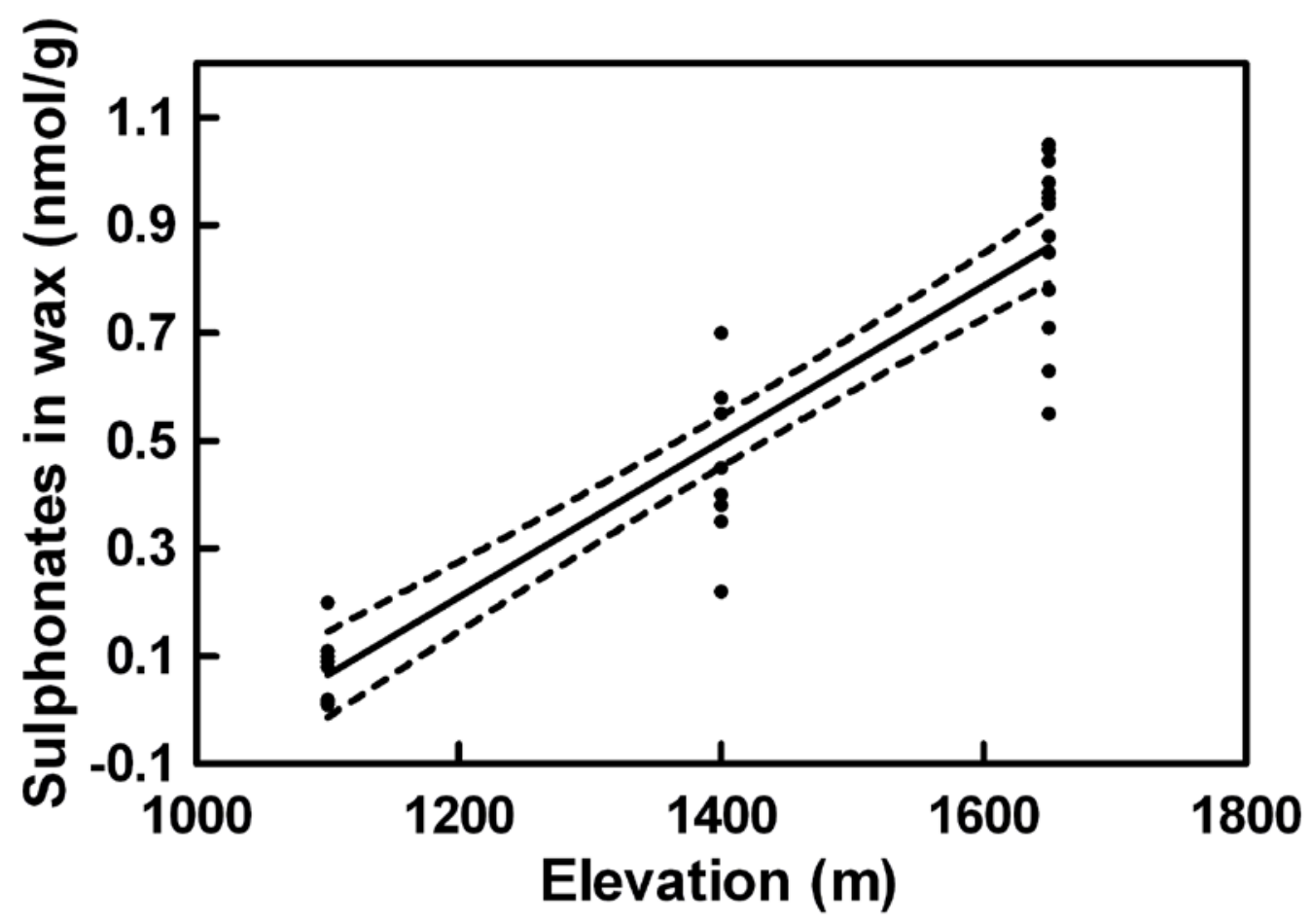

Fig. 4 Linear regression of sulphonate concentrations in pine needle wax against elevation intervals (slope significantly different from zero $\mathrm{p}<0.0001 ; \mathrm{r}^{2}=0.876$ ). 95\% confidence bands are shown. 